\title{
EDITORIAL
}

\section{Thank you to the outgoing editorial team}

\author{
D. Wallwiener • J. Dequesne • G.B. Melis
}

Published online: 21 November 2006

(C) Springer-Verlag 2006

Dear members of the European Society of Gynaecological Surgery,

Dear colleagues,

Over the past quarter century, we have seen the establishment of endoscopy as the third pillar of gynaecologic surgery. Abdominal surgery, vaginal surgery and endoscopic surgery offer us the wide range of therapeutic options needed to optimally deal with the individual problems of our patients. The spectacular success of endoscopy has been driven by the forces of innovation, the philosophy of minimal trauma and the willingness to look at old problems in the new light of multimodality. We have today at our disposal an armamentarium of technology and techniques to deal with every conceivable diagnosis and surgical problem.

What initially started as a selective society for highly experienced laparoscopic gynaecological surgeons has opened its doors to all gynaecologists with an interest in modern surgical technologies.

One of our most important communication tools is our own scientific journal. Today, you are reading the 12th issue of this journal -Gynecological Surgery: Endoscopy, Imaging, and Allied Techniques.

This scientific journal is the platform for publication of original scientific work for the members of the ESGE as well as a portal to communicate new and innovative techniques that are essential for the progress which the ESGE symbolises.

After 3 years of tremendous hard work for the journal and the society, Peter O'Donovan has, as planned, handed over his responsibility as Editor-in-Chief. His task was to implement and profile the journal in the scientific community as well as to stay in contact with the commercial sponsors.

You can imagine the pile of work that needed to be done, starting from scratch and building up to the high scientific standards the journal nowadays stands for. More than 1,200 subscriptions to the journal and its worldwide distribution are only two of the marvellous accomplishments of his editorship. All scientific submissions are peer-reviewed under his organization. We want to thank him as well as his assistant, Rachel Costigan, for their outstanding work.

D. Wallwiener $(\square) \cdot$ J. Dequesne $\cdot$ G.B. Melis

Editorial Office,

Tiensevest 168 ,

3000 Leuven, Belgium

e-mail: infojournal@esge.org
Prof. Ivo Brosens, the new Editor-in-Chief, would like to continue this way in the future. The high amount of work that has to be done to manage such a journal is reflected by Prof. Brosens' decision to assign Associate Editors who will take care of special fields of interest.

To guarantee this high impact, each member of the society is recommended to support our journal by contributing scientific work of a high standard. The Editorial Board and the newly appointed Associate Editors represent the leading practitioners in gynaecological surgery in all European countries.

They will, together with the Editor-in-Chief, shorten review times and provide a peer-review process to guarantee a high scientific standard.

Thus, Gynecological Surgery will be the leading journal in its field and I am sure that the society as a whole, as well as each individual member, will benefit greatly.

We want to thank all those who have supported our work in recent years. Without them, our efforts would not have been as successful.

Three years of Gynecological Surgery - a lot of work. I sincerely want to thank Peter O'Donovan and Rachel Costigan for all their effort. Peter will surely continue to play an important role within our society.

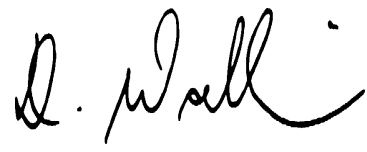

D. Wallwiener

Chairman, Journal

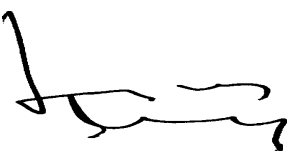

J. Dequesne

Past president

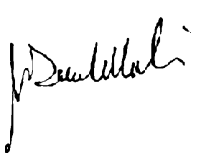

G.B. Melis

President 